\title{
EDITORIAL
}

\section{Is homosexual behaviour hard-wired? Sexual orientation and brain structure $^{1}$}

The search for neurobiological explanations for human behaviours is in full flow, spurred on by the same reductionist philosophy and technological advances that are proving so dominant in the investigation of psychiatric diseases. Homosexuality is no exception, with recent studies reporting on its possible genetic basis (Hamer et al. 1993) and biological correlates (Byne \& Parsons, 1993). One area of research that has received much attention concerns neuroanatomical differences in homosexual compared to heterosexual men. Although the authors are always careful to point out the limitations of the data and the caution with which they should be interpreted, the implication is that these structural differences are causally involved in producing homosexual orientation. This viewpoint leads to a number of possible conclusions regarding homosexuality and homosexuals. For example, if their brains are different from heterosexuals, it might be decided that homosexuals: (1) cannot be held responsible for their sexual actions and should be legally immune from discrimination; (2) should be viewed as a normal variant, perhaps akin to left-handed people; (3) should be redefined as suffering from a brain disease; or (4) require neurosurgical intervention. Before becoming embroiled in these far-reaching issues, it is necessary to ask how firm the evidence is upon which such arguments would be constructed.

\section{THE NEUROANATOMICAL BACKGROUND}

The experimental justification for research into structural brain differences associated with sexual orientation has come mainly from studies in rats. Several regions in the rodent hypothalamus are sexual dimorphic - that is, they are larger and contain more cells in one sex than the other (Bleier et al. 1982). These nuclei lie in the pre-optic area and elsewhere in the hypothalamus, the best characterized example being the sexual dimorphic nucleus (SDN; Gorski et al. 1978); its equivalent in humans is called the first interstitial nucleus of the anterior hypothalamus (INAH 1; LeVay, 1991; Swaab et al. 1992), also known as the intermediate nucleus (Braak \& Braak, 1987). (For a review of the complex anatomy and nomenclature of the human hypothalamus, see Saper (1990) and Swaab et al. (1993).) It is generally assumed that their sexual dimorphism means that these nuclei have a major role in sexual and reproductive matters, a belief that has been supported by experimentally induced lesions, which produce changes in sexual behaviour. One important measure is the lordosis that can be produced in male rats by which they allow themselves to be mounted and which is interpreted as rodent homosexual behaviour. Lesioning the SDN in male rats, for example, has been reported to produce lordosis and to affect libido (De Jonge et al. 1989).

These studies provided the rationale for studying the equivalent nuclei in human brain. In the event, the nucleus that was expected to prove sexually dimorphic, the putative human SDN (INAH 1), has only shown sex differences in one (Swaab \& Fliers, 1985) out of three studies (Allen et al. 1989; LeVay, 1991). While failing to replicate the finding of sexual dimorphism in INAH 1, Allen and colleagues reported on three other, previously unrecognized, nuclei, called INAH 2-4. They found that INAH 3, and possibly INAH 2, were sexually dimorphic (Allen et al. 1989). The sexual dimorphism in INAH 3, but not INAH 2, has been confirmed (LeVay, 1991). Sexual differences have also been reported for the corpus callosum and other inter-hemispheric tract, the anterior commissure (Allen et al. 1991).

1 Address for correspondence: Dr Paul J. Harrison, University Department of Psychiatry, Warneford Hospital, Oxford OX3 7JX. 


\section{NEUROANATOMICAL DIFFERENCES IN HOMOSEXUAL MEN}

With the identification of these apparently sexually dimorphic regions in human brain, and the evidence that the homologous structures in rodents are involved in sexual behaviour, attention turned to a comparison of these regions between homosexuals and heterosexuals. It was predicted that the morphological characteristics of these areas in homosexual men might be similar to that in (heterosexual) women, a prediction based in part on the simplistic assumption that homosexual men are, in hypothalamic terms, like women (Dörner, 1988). The ability to carry out this work has come from the epidemic of AIDS, which has provided an unprecedented source of post mortem brain tissue from known homosexual men. There has been no equivalent availability of brains from lesbians and nothing is known of differences that might exist in the structure of their brains. However, the theoretical issues raised by the data to be discussed here would apply equally to any alterations that were to be found.

There have been three studies reporting structural brain differences in homosexual men compared with heterosexual men (summarized in Table 1). The first report was that of Swaab \& Hofman (1990). On the basis of the sexual dimorphism that had been found for the SDN (INAH 1) (Swaab \& Fliers, 1985), they predicted that any structural brain differences with regard to sexual orientation would affect this nucleus. However, the SDN was unchanged in homosexual men. Instead, a difference was identified in another hypothalamic nucleus, namely, the suprachiasmatic nucleus (SCN). The SCN was found to be larger and contained more neurons in homosexual men who had died of AIDS, compared with heterosexual men dying of other causes, and with a group of heterosexual men and women who had died of AIDS.

The study which caught the public's attention was that of LeVay (1991), who examined the volume of INAH 1-4. He predicted, on the basis of the sexual dimorphisms found by Allen $e t$ al. (1989), that INAH 2 and 3 would be smaller in individuals attracted to men (i.e. homosexual men and heterosexual women) than in those individuals who were attracted to women (i.e. heterosexual men and homosexual women). In fact, only INAH 3 showed a relationship with sexual orientation, being less than half the size in homosexual as in heterosexual men, such that the INAH 3 of homosexual men was similar in size to that of women (Table 1). These differences persisted when only men who had died of AIDS were included for comparison.

Allen \& Gorski (1992) described a difference in homosexual men in the anterior commissure, a

Table 1. Neuroanatomical differences reported in the brains of homosexual men

\begin{tabular}{|c|c|c|c|}
\hline & Swaab \& Hofman $(1990)^{*}$ & LeVay (1991) & Allen \& Gorski (1992) \\
\hline Homosexual men $(N)$ & 10 & 19 & 30 \\
\hline $\begin{array}{r}\text { Heterosexual men }(N) \\
\text { Dying of AIDS }(N)\end{array}$ & $\begin{array}{r}10 \\
18 \\
4\end{array}$ & $\begin{array}{r}16 \\
6\end{array}$ & $\begin{array}{r}30 \\
6\end{array}$ \\
\hline $\begin{array}{l}\text { Heterosexual women }(N) \\
\text { Dying of AIDS }(N)\end{array}$ & $\begin{array}{l}2 \\
2\end{array}$ & $\begin{array}{l}6 \\
1\end{array}$ & $\begin{array}{r}30 \\
0\end{array}$ \\
\hline Structure measured $\dagger$ & $\mathrm{SCN}$ & INAH ! -4 & Anterior commissure \\
\hline Parameter measured & Volume, cell counts & Volume & Cross-sectional area \\
\hline $\begin{array}{l}\text { Main differences in } \\
\text { homosexual } v \text {. } \\
\text { heterosexual men }\end{array}$ & $\begin{array}{l}\text { (1) SCN } 1.7 \times \text { larger and has } \\
2 \cdot 1 \times \text { as many cells } \\
\text { (2) INAH I unaltered }\end{array}$ & $\begin{array}{l}\text { (1) INAH } 360 \% \\
\text { smaller } \\
\text { (2) INAH } 1,2 \text { and } 4 \\
\text { unaltered }\end{array}$ & One-third larger \\
\hline Statistical significance & $P<0.01 \pm$ & $P<0.001 \S$ & $P<0.00019$ \\
\hline
\end{tabular}

* Although the sample numbers are summarized here, their division of cases did not correspond exactly to these three groups. For details see text.

† INAH: interstitial nuclei of the anterior hypothalamus; SCN: suprachiasmatic nucleus.

$\ddagger$ Kruskal-Wallis multiple comparison test.

$\S$ ANOVA and Monte Carlo procedure.

If ANOVA and Bonferroni $t$ procedure or Mann-Whitney test. 
fibre tract just above the hypothalamus that conveys sensory information between the temporal lobes. Their rationale for measuring this structure was their previous finding that it is larger in women than men (Allen et al. 1991). They argued that, since the anterior commissure is not thought to be involved in reproductive functions, any such changes would mitigate against a single brain structure being associated with sexual orientation, but rather that there are more widespread cerebral differences in homosexuals. The cross-sectional area of the anterior commissure in the midline was measured in 30 homosexual men, 30 heterosexual men and 30 heterosexual women, individually matched for age. In homosexual men, the anterior commissural area was $34 \%$ larger than in heterosexual men and $18 \%$ larger than in heterosexual women. Correcting for total brain weight, its area remained greater in homosexual men than heterosexual men but was similar to that in women. The difference was also found when comparing the men in each group who died with or without AIDS.

In summary, in homosexual compared to heterosexual men, three structures in the brain are reported to be different: one hypothalamic nucleus, INAH 3, is smaller (LeVay, 1991), while another, the SCN, is larger (Swaab \& Hofman, 1990), as is one of the connecting pathways between the cerebral hemispheres, the anterior commissure (Allen \& Gorski, 1992).

\section{LIMITATIONS OF THE DATA}

In all three studies, the measurements were carried out with the researcher 'blind' to the sexual orientation of the case. Potential confounders such as age, post mortem delay and coincidental neuropathologies were controlled for and can also be considered unlikely. HIV is known to be neurotoxic and to affect neocortical neuronal density (Everall et al. 1991); however, the complicating effect of HIV appears to have been removed by demonstrating similar changes in the subgroups matched for the presence of AIDS. The attention paid to these factors suggests that, though one may argue about their interpretation, the data appear to be methodologically and statistically robust. Certainly all the publications originated from eminent researchers and were published in first-rank journals. Before discussing what the results might mean, however, several technical issues remain to be highlighted.

There are well-known, yet often overlooked, problems with studies where sizes of brain nuclei or the number or density of neurons within a region are measured. For example, the type and duration of brain fixation prior to embedding of the tissue affects in a complex way the degree of tissue shrinkage, which in turn will affect parameters of size and cell density. It is, therefore, essential to control for these variables carefully between groups. The thickness of tissue sections, tissue staining and the method used for cell counting can also introduce bias into the analysis; for instance, by overestimating the proportion of large neurons. Although there are now procedures which largely overcome these problems (Pakkenberg \& Gundersen, 1988), they were not used in the studies of Swaab \& Hofman (1990) or LeVay (1991). Additionally, it is difficult to ensure that the orientation of tissue blocks, and of sections cut from each block, are comparable between cases. This is especially true for the hypothalamic region (Saper, 1990) and is compounded by the very small size of the nuclei being measured, e.g. $0.05 \mathrm{~mm}^{3}$ for the female human INAH 3 (Allen et al. 1989). Clearly, sections cut at a tangent to the intended plane will not produce the correct value for the cross-sectional area of a structure (as used by Allen \& Gorski, 1992), and will be problematical if the volume of a structure is calculated by reconstructing it from a series of sections (as used by LeVay, 1991). Thus, even though the analyses of all three studies were carried out blind to sexual orientation of the cases, and given that there is no reason to suppose that any of these confounding factors were systematically different between groups, they each provide a source of potentially erroneous data. Further discussion of these issues is hampered by the lack of experimental detail in the papers, especially that of LeVay (1991).

There are methodological issues apart from the technicalities of morphometric studies. The matching of subgroups for the presence or absence of HIV does not wholly prevent this from being a confounding factor since the nature and course of the illness depends, to a degree, on how the virus was acquired. For example, at least in the USA, homosexual men who are dying from AIDS tend 
to have more complications and receive more care than people who become infected with HIV via drug use (Byne \& Parsons, 1993). Importantly, the neuropathological features of the two AIDS groups also vary (Lantos et al. 1989; Bell et al. 1993) and may, therefore, have affected the hypothalamic structures differentially. In addition, testosterone levels are reduced in HIV infection (Croxson et al. 1989). This may confound measurements of hypothalamic nuclei that are regulated (at least in rodents) by gonadal steroids (Murakami \& Arai, 1989). This hormonal sensitivity occurs primarily during critical developmental periods, but there is evidence of persistent testosterone sensitivity in adult animals also (Commins \& Yahr, 1984). Moreover, the findings of Swaab \& Hofman (1990) may be confounded by their subsequent report that SCN size varies considerably according to season (Hofman et al. 1993). The seasonality effect illustrates the plasticity of the human brain and how component structures may be affected by many influences of which sexual orientation is but one candidate. A separate issue concerns the fact that the sexual orientation of the heterosexual men and women in these studies was assumed if the case notes did not indicate otherwise. The possibility of unsuspected homosexuality or bisexuality in these groups cannot be excluded. Indeed, the design and analysis of the studies is based upon sexual orientation being a dichotomous variable; more generally, the issue of the heterogeneity of sexual orientation and of homosexual behaviour is neglected. In this regard, the measured variables in all three studies showed a considerable overlap between heterosexuals and homosexuals. Either this indicates the presence of misdiagnosed sexual orientation in the samples, or else it precludes any of the changes from having a necessary or sufficient relationship with sexual orientation. Finally, none of the positive findings has been replicated (or refuted) by other workers studying a separate series of brains. They are, therefore, subject to the caveats applicable to all unconfirmed results obtained on small samples.

\section{PROBLEMS OF DATA INTERPRETATION}

These considerations together mean that the data of Swaab \& Hofman (1990), LeVay (1991) and Allen \& Gorski (1991) should be viewed cautiously. Assuming the data themselves prove to be correct, important questions about their interpretation remain. The rodent work provides, at best, a modest rationale for the human studies for several reasons. The assumption that a male rat allowing itself to be mounted provides an adequate model of the diverse aspects of homosexuality in men is questionable. Also, the evidence for sexual dimorphisms in experimental animals is in places equivocal as is the evidence that selective lesions produce reliable effects of any magnitude on sexual behaviours. For example, the results of SDN lesions may reflect damage to the overlying hypothalamic area rather than to the SDN itself (Arendash \& Gorski, 1983). Neither, despite the description of INAH 1 given above, is it entirely clear which hypothalamic nucleus, if any, is the precise human homologue of the rodent SDN (Allen et al. 1989; Saper, 1990), or to what extent cross-species anatomical or functional comparisons can validly be made. Finally, two of the areas found to be different in homosexuals, the SCN and anterior commissure, have not otherwise been linked to any aspect of sexuality, partly because the size of the SCN is not sexually dimorphic (Swaab \& Fliers, 1985) while that of the anterior commissure remains uncertain (Demeter et al. 1988). Any explanation for their involvement in sexual orientation is, therefore, largely a post hoc rationalization, notwithstanding the reasoning of Allen et al. (1991); conversely the nucleus, which was initially predicted to differ in homosexuals, the SDN (INAH 1) does not (Swaab \& Hofman, 1990; LeVay, 1991), and in this respect the original hypothesis has been falsified.

The overriding issue of interpretation, however, is the question of association versus causality. In very simple terms, the following three possible correlations between brain structure and sexual orientation can be envisaged. (1) Homosexual behaviour is indeed hard-wired and is caused directly by the differences in brain structure. Men are destined to be homosexual because, for whatever aetiological reason, the processes of neurodevelopment result in a nucleus or tract of abnormal size or neuronal constitution, and the effect of this difference is to produce a homosexual orientation. As LeVay wryly puts it, 'gay men simply don't have the brain cells to be attracted to women' (LeVay, 1993, p. 121). For example, the genetic locus that predisposes to male homosexuality 
(Hamer et al. 1993) might do so because it contains a gene encoding a hypothalamic growth factor, which is abnormal in these men. Within the overall standpoint of a causal connection between brain structure and sexual orientation, two further interpretations are possible. Either the data place homosexuality into a similar relationship with brain structure as other normal characteristics like handedness (Witelson \& Nowakowski, 1991) and intelligence (Andreasen et al. 1993), or they might mean that homosexuality comes into the same category as abnormal conditions exhibiting subtle histological differences, such as schizophrenia (Roberts, 1991) or dyslexia (Galaburda et al. 1985). In other words, even accepting that there is a causal relationship between brain differences and homosexual orientation would not mean that homosexuality is a disorder, since the question of whether a difference in a biological variable is pathological or merely a normal variant requires many other factors to be taken into account (Reznek, 1987). It may be, for example, that one could discover that predilections for particular heterosexual acts also each have a neuroanatomical basis. (2) Homosexuality is caused by other processes, such as stress or parental characteristics; the pathogenic mechanisms also induce structural differences in the brain, which are an epiphenomenon and play no direct part in producing homosexuality. In passing, it is important to note that the prevalence of homosexual behaviour is undoubtedly determined in part by cultural factors (Byne \& Parsons, 1993). Any aetiological explanation of homosexual behaviour based on neuroanatomy would ultimately have to explain how such psychosocial factors exert their effects (see also Baron, 1993). (3) Homosexual thoughts and/or behaviour lead to chemical and structural changes in the brain in the same way as many forms of experience, such as social deprivation and environmental complexity (Walsh, 1981; Martin et al. 1991). For example, the promiscuous behaviour and associated lifestyle likely to have been common among homosexual men who die of AIDS may cause selective shrinkage of a subset of hypothalamic neurons or increase the calibre of anterior commissural fibres. Nothing in the current data allows any of these hypotheses to be confirmed or refuted. All that has been shown is a possible association between the size of certain brain regions and male sexual orientation.

The studies need to be replicated and extended, given their potential significance and current shortcomings. Attention should be paid to the methodological issues outlined here, ranging from the prospective acquisition of extensive personal, psychosexual and clinical details about the cases, through to more sophisticated morphometric analyses. Interpretation of the data would be helped by more conclusive and specific information on the functions of the affected structures, even if this has to be by extrapolation from rodents. It would also be of interest to examine other regions that are sexually dimorphic in rats, such as the ventromedial hypothalamic nucleus (Matsumoto \& Arai, 1983) and to look for sex differences in innervation (Micevych et al. 1987; Simerly et al. 1987, 1988), efferent connectivity (Finn et al. 1993) and synaptic organization (Raisman \& Field, 1973), which exist in rodents and which might accompany structural hypothalamic alterations in homosexuals. Although addressing these issues cannot greatly clarify the causality of any relationship between brain structure and male homosexuality, the findings would put the data regarding the brains of homosexual men on much firmer theoretical and empirical foundations.

\section{CONCLUSIONS}

The demonstration of differences between the brains of homosexuals and heterosexuals is a tangible and, on the surface, convincing example of how complex behaviours can be understood in biological terms. However, the significance of this 'hard-wired' explanation of sexual orientation depends entirely upon the quality and quantity of the data. At present, this does not warrant anything other than a very cautious discussion of its meaning. Even if one or more of the reported changes are confirmed, the causal nature of their association with homosexuality will remain to be demonstrated. This is likely to prove difficult. The danger is that the broader implications of the structural model - in terms of legal, ethical and even therapeutic issues - may be given greater attention than is currently justified.

\section{P. J. HARRISON, I. P. EVERALL AND J. CATALAN}

We thank Dr Michael Sharpe for helpful comments. I.P.E. is an MRC Clinician Scientist. 


\section{REFERENCES}

Allen, L. S. \& Gorski, R. A. (1992). Sexual orientation and the size of the anterior commissure in the human brain. Proceedings of the National Academy of Sciences, USA 89, 7199-7202.

Allen, L. S., Hines, M., Shryne, L. E. \& Gorski, R. A. (1989). Two sexually dimorphic cell groups in the human brain. Journal of Neuroscience 9, 497-506.

Allen, L. S., Richey, M.. F., Chai, Y. M.\& Gorski, R. A. (1991). Sex differences in the corpus callosum of the living human being. Journal of Neuroscience 11, 933-942.

Andreasen, N. C., Flaum, M., Swayze, V., II., O'Leary, D. S., Alliger, R., Cohen, G., Ehrhardt, J. \& Yuh, W. T. C. (1993). Intelligence and brain structure in normal individuals. American Journal of Psychiarry 150, 130-134.

Arendash, G. W. \& Gorski, R. W. (1983). Effects of discrete lesions of the sexually dimorphic nucleus of the preoptic area or other medial preoptic regions on the sexual behaviour of male rats. Brain Research Bulletin 10, 147-154.

Baron, M. (1993). Genetic linkage and male homosexual orientation. British Medical Journal 307, 337-338.

Bell, J., Arango, C., Ironside, J., Donaldson, Y., Rebus, S., Simmonds, P.\& Peutherer, J. (1993). Different neuropathological findings in homosexuals and drug abusers with AIDS. Clinical Neuropalhology 12, $\mathrm{S} 8$.

Bleier, R., Byne, W. \& Siggelkow, I. (1982). Cytoarchitectonic sexual dimorphisms of the medial preoptic and anterior hypothalamic areas in guinea pig, rat, hamster and mouse. Journal of Comparative Neurology 212, 118-130.

Braak, H. \& Braak, E. (1987). The hypothalamus of the human adult: chiasmatic region. Anatomy and Embryology 176, 315-330.

Byne, W. \& Parsons, B. (1993). Human sexual orientation. The biologic theories reappraised. Archives of General Psychiatry 50, 228-239.

Commins, D. \& Yahr, P. (1984). Adult testosterone levels influence the morphology of a sexually dimorphic area in the Mongolian gerbil brain. Journal of Comparative Neurology 224, 132-140.

Croxson, T. S., Chapman, W. E., Miller, L. K., Levit, C. D., Senie, R. \& Zumoff, B. (1989). Changes in the hypothalamic-pituitarygonadal axis in human immunodeficiency virus-infected homosexual men. Journal of Clinical Endocrinology and Metabolism 68 , 317-321.

De Jonge, F. H., Louwerse, A. L., Ooms, M. P., Evers, P., Endert, E. \& Van de Poll, N. E. (1989). Lesions of the SDN-POA inhibit sexual behaviour of male Wistar rats. Brain Research Bulletin 23, 483-492.

Demeter, S., Ringo, J. L. \& Doty, R. W. (1988). Morphometric analysis of the human corpus callosum and anterior commissure. Human Neurobiology 6, 219-226.

Dörner, G. (1988). Neuroendocrine response to estrogen and brain differentiation in heterosexuals, homosexuals and transsexuals. Archives of Sexual Behaviour 17, 57-75.

Everall, I. P., Luthert, P. J. \& Lantos, P. L. (1991). Neuronal loss in the frontal cortex in HIV infection. Lancet 337, 1119-1121.

Finn, P. D., De Vries, G. J. \& Jahr, P. (1993). Efferent projections of the sexually dimorphic area of the gerbil hypothalamus: anterograde identificatioin and retrograde verification in males and females. Journal of Comparative Neurology 338, 491-520.

Galaburda, A. M., Sherman, G. P., Rosen, G. D., Aboitiz, F. \& Geschwind, N. (1985). Developmental dyslexia: four consecutive patients with cortical abnormalities. Annals of Neurology 8, 222-223.

Gorski, R. A., Gordon, J. H., Shryne, J. E. \& Southam, A. M. (1978). Evidence for a morphological sex difference within the medial preoptic area of the rat brain. Brain Research 148, 333-346.
Hamer, D. H., Hu, S., Magnuson, V. L., Hu, N. \& Pattatucci, A. M. L. (1993). A linkage between DNA markers on the $\mathrm{X}$ chromosome and male sexual orientation. Science 261, 321-327.

Hofman, M. A., Purba, J. \& Swaab, D. F. (1993). Annual variation in the vasopressin neuron population of the human suprachiasmatic nucleus. Neuroscience 53, 1103-1112.

Lantos, P. L., McLaughlin, J. E., Scholtz, C. L., Berry, C. L. \& Tinghe, J. R. (1989). Neuropathology of the brain in HIV infection. Lancet i, 309-311.

LeVay, S. (1991). A difference in hypothalamic structure between heterosexual and homosexual men. Science 253, 1034-1037.

LeVay, S. (1993). The Sexual Brain. MIT Press: Cambridge, Mass.

Martin, L. J., Spicer, D. M., Lewis, M. H., Gluck, J. P. \& Cork, L. C. (1991). Social deprivation of infant rhesus monkeys alters the chemoarchitecture of the brain. 1. Subcortical regions. Journal of Neuroscience 11, 3344-3358.

Matsumoto, A. \& Arai, Y. (1983). Sex differences in volume of the ventromedial nucleus of the hypothalamus in the rat. Endocrinology (Japan) 30, 277-280.

Micevych, P., Akesson, T. \& Elde, R. (1987). The distribution of cholecystokinin-immunoreactive cell bodies in the male and female rat. I. Hypothalamus. Journal of Comparative Neurology 255, 124-136.

Murakami, S. \& Arai, Y. (1989). Neuronal death in the developing sexually dimorphic periventricular nucleus of the preoptic area in the female rat: effect of neonatal androgen treatment. Neuroscience Letters 102, 185-190.

Pakkenberg, B. \& Gundersen, H. J. G. (1988). Total number of neurons and glial cells in human brain nuclei estimated by the disector and the fractionator. Journal of Microscopy 150, 1-20.

Raisman, G. \& Field, P. M. (1973). Sexual dimorphism in the neuropil of the preoptic area of the rat and its dependence on neonatal androgen. Brain Research 54, 1-29.

Reznek, L. (1987). The Nature of Disease. Routledge \& Kegan Paul: London.

Roberts, G. W. (1991). Schizophrenia: a neuropathological perspective. British Journal of Psychiatry 158, 8-17.

Saper, C. B. (1990). Hypothalamus. In The Human Nervous System (ed. G. Paxinos), pp. 389-413. Academic Press, San Diego.

Simerly, R. B., Swanson, L. W., Handa, R. J. \& Gorski, R. A. (1987). Influence of perinatal androgen on the sexual dimorphic distribution of tyrosine hydroxylase-immunoreactive cells and fibers in the anteroventral periventricular nucleus of the rat. Neuroendocrinology 40, 501-510.

Simerly, R. B., McCall, L. D. \& Watson, S. J. (1988). Distribution of opioid peptides in the pre-optic region: immunohistochemical evidence for a steroid-sensitive enkephalin sexual dimorphism. Journal of Comparative Neurology 276, 442-459.

Swaab, D. F. \& Fliers, E. (1985). A sexually dimorphic nucleus in the human brain. Science 228, 1112-1114.

Swaab, D. F. \& Hofman, M. A. (1990). An enlarged suprachiasmatic nucleus in homosexual men. Brain Research 537, 141-148.

Swaab, D. F., Gooren, L. J. G. \& Hofman, M. A. (1992). The human hypothalamus in relation to gender and sexual orientation. Progress in Brain Research 93, 205-219.

Swaab, D. F., Hofman, M. A., Lucassen, P. J., Purba, J. S., Raadshher, F.C. \& Van de Nes, J.A.P. (1993). Functional neuroanatomy and neuropathology of the human hypothalamus. Anatomy and Embryology 187, 317-330.

Walsh, R. N. (1981). Effects of environmental complexity and deprivation on brain anatomy and histology: a review. International Journal of Neuroscience 12, 33-51.

Witelson, S. F. \& Nowakowski, R. S. (1991). Left out axons make men right: a hypothesis for the origin of handedness and functional asymmetry. Neuropsychologica 29, 327-333. 